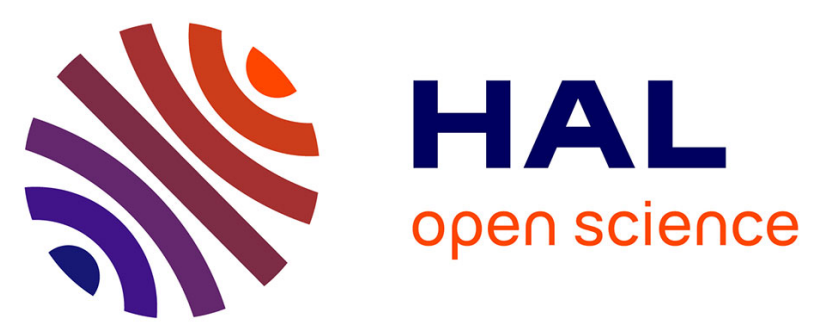

\title{
CANCERIZATION OF CUTANEOUS FLAP RECONSTRUCTION FOR ORAL SQUAMOUS CELL CARCINOMA: REPORT OF THREE CASES STUDIED WITH THE mtDNA D-LOOP SEQUENCE ANALYSIS
}

Maria Pia Foschini, Luca Morandi, Claudio Marchetti, Roberto Cocchi, Leonardo Henry Eusebi, Anna Farnedi, Giovanni Badiali, Davide Bartolomeo Gissi, Maria Gabriella Pennesi, Lucio Montebugnoli

\section{To cite this version:}

Maria Pia Foschini, Luca Morandi, Claudio Marchetti, Roberto Cocchi, Leonardo Henry Eusebi, et al.. CANCERIZATION OF CUTANEOUS FLAP RECONSTRUCTION FOR ORAL SQUAMOUS CELL CARCINOMA: REPORT OF THREE CASES STUDIED WITH THE mtDNA D-LOOP SEQUENCE ANALYSIS. Histopathology, 2011, 58 (3), pp.361. 10.1111/j.1365-2559.2011.03754.x . hal-00610739

\author{
HAL Id: hal-00610739 \\ https://hal.science/hal-00610739
}

Submitted on 24 Jul 2011

HAL is a multi-disciplinary open access archive for the deposit and dissemination of scientific research documents, whether they are published or not. The documents may come from teaching and research institutions in France or abroad, or from public or private research centers.
L'archive ouverte pluridisciplinaire HAL, est destinée au dépôt et à la diffusion de documents scientifiques de niveau recherche, publiés ou non, émanant des établissements d'enseignement et de recherche français ou étrangers, des laboratoires publics ou privés. 


\section{Histopathology}

\section{CANCERIZATION OF CUTANEOUS FLAP RECONSTRUCTION FOR ORAL SQUAMOUS CELL CARCINOMA: REPORT OF THREE CASES STUDIED WITH THE mEDNA D-LOOP SEQUENCE ANALYSIS}

\begin{tabular}{|c|c|}
\hline Journal: & Histopathology \\
\hline Manuscript ID: & HISTOP-01-10-0028.R1 \\
\hline Manuscript Type: & Original Article \\
\hline $\begin{array}{r}\text { Date Submitted by the } \\
\text { Author: }\end{array}$ & 28-Feb-2010 \\
\hline Complete List of Authors: & $\begin{array}{l}\text { Foschini, Maria; University of Bologna, Section of Anatomic } \\
\text { Pathology, Department of Haematology and Oncology "L. And A. } \\
\text { Seragnoli", Bellaria Hospital } \\
\text { Morandi, Luca; University of Bologna, Section of Anatomic } \\
\text { Pathology, Department of Haematology and Oncology "L. And A. } \\
\text { Seragnoli", Bellaria Hospital } \\
\text { Marchetti, Claudio; University of Bologna, Department of Oral and } \\
\text { Maxillofacial Surgery, S. Orsola-Malpighi Hospital } \\
\text { Cocchi, Roberto; Bellaria Hospital, Department of Maxillo-Facial } \\
\text { Surgery } \\
\text { Eusebi, Leonardo; University of Bologna, Section of Anatomic } \\
\text { Pathology, Department of Haematology and Oncology "L. And A. } \\
\text { Seragnoli", Bellaria Hospital } \\
\text { Farnedi, Anna; University of Bologna, Section of Anatomic } \\
\text { Pathology, Department of Haematology and Oncology "L. And A. } \\
\text { Seragnoli", Bellaria Hospital } \\
\text { Badiali, Giovanni; University of Bologna, Department of Oral and } \\
\text { Maxillofacial Surgery, S. Orsola-Malpighi Hospital } \\
\text { Gissi, Davide; University of Bologna, Department of Oral Sciences } \\
\text { Pennesi, Maria; Bellaria Hospital, Department of Maxillo-Facial } \\
\text { Surgery } \\
\text { montebugnoli, lucio; University of Bologna, Department of Oral } \\
\text { Sciences }\end{array}$ \\
\hline Keywords: & Oral cancer, skin graft, cutaneous flap, mitochondrial DNA D-loop \\
\hline
\end{tabular}




\section{CANCERIZATION OF CUTANEOUS FLAP RECONSTRUCTION FOR ORAL SQUAMOUS CELL CARCINOMA: REPORT OF THREE CASES STUDIED WITH THE mtDNA D-LOOP SEQUENCE ANALYSIS.}

Foschini Maria P, ${ }^{1}$ Morandi Luca, ${ }^{1}$ Marchetti Claudio, ${ }^{2}$ Cocchi Roberto, ${ }^{3}$ Eusebi Leonardo Henry, ${ }^{1}$ Farnedi Anna, ${ }^{1}$ Badiali Giovanni, ${ }^{2}$ Gissi Davide Bartolomeo, ${ }^{4}$ Pennesi Maria G, ${ }^{3}$ Montebugnoli Lucio. ${ }^{4}$

${ }^{1}$ Section of Anatomic Pathology, Department of Haematology and Oncology "L. And A. Seragnoli", Bellaria Hospital, University of Bologna, Bologna, Italy

2 Department of Oral and Maxillofacial Surgery, S. Orsola-Malpighi Hospital, University of Bologna, Bologna, Italy

${ }^{3}$ Department of Maxillo-Facial Surgery, Bellaria Hospital, Bologna, Italy

${ }^{4}$ Department of Oral Sciences, University of Bologna, Bologna, Italy

Running title: Cutaneous flap cancerization.

Key words: Oral cancer, skin graft, cutaneous flap, mitochondrial DNA D-loop.

\section{Corresponding author:}

Maria P. Foschini, MD

Section of Anatomic Pathology,

Department of Haematology and Oncology "L. And A. Seragnoli"

University of Bologna,

Bellaria Hospital,

Via Altura 3, 40139 Bologna, Italy

Tel: +390516225006

Fax: +390516225759

E-mail: Mariapia.foschini@unibo.it 


\section{ABSTRACT}

\section{Aims}

Tissue defects, resulting from surgical resection of oral squamous cell carcinoma (OSCC), are routinely reconstructed with skin graft. OSCC arising from the grafted skin have been described, however, it is still unclear whether primary and second tumours have a common clonal origin. By screening mitochondrial DNA D-loop region (mtDNA), we evaluated the clonal relationship between the primary OSCC and the second neoplastic features appearing in the skin graft in three patients.

\section{Methods and Results}

In all the three cases, the neoplastic lesions arising in the skin graft showed a clonal relationship with the previous OSCC and, on the basis of the results obtained with the mtDNA analysis, could be considered a recurrence of the primary OSCC rather than a second primary OSCC.

\section{Conclusions}

Starting from a field of genetically altered cells of the oral mucosa, the spreading of the clonal cell population to the cutaneous flap might be stimulated by cytokines produced by the grafted skin. More studies are needed to evaluate the molecular relationship between primary and second OSCC to identify patients at higher risk of developing a second tumour of the skin graft. 


\section{INTRODUCTION}

Oral squamous cell carcinoma (OSCC) is the most common type of cancer affecting the oral cavity. Despite its frequency, diagnoses are often delayed and in order to achieve complete tumour removal, major surgical resections are needed. More extensive eradications of OSCC are possible since tissue defects, resulting from surgical resection, are routinely reconstructed with skin flaps obtained from radial forearm including a microvascular anastomosis for attachment at the site of reconstruction. ${ }^{1}$

Recurrences and second primary OSCC are not uncommon in the oral cavity with a development rate of $2-3 \%$ of new cases per year. ${ }^{2}$

Several cases of squamous cell carcinoma or dysplasia arising from the grafted skin have been described (table 1); however, knowledge on behaviour and modification in the grafted skin is still scanty. ${ }^{3,4}$

In 1953, Slaughter and colleagues introduced the concept of "Field cancerization" as a pathogenic pathway for multiple primary OSCC arising in different areas, associated to pre-neoplastic lesions. ${ }^{5}$ The Authors ${ }^{5}$ based the concept of "Field cancerization" on histological observations from OSCCs and associated pre-neoplastic lesions, such as dysplasia or in situ carcinoma, developed in different areas of a single patients. ${ }^{5}$

Subsequently, the concept of field cancerization was sustained by further clinical and histological evidence, and in the last decade several studies, based on molecular techniques, evaluated the genetic basis of this concept. Indeed, this observation was considered of crucial importance to differentiate recurrences from second primary OSCC. 
Furthermore, the oral mucosa undergoes malignant transformation through the development of genetically altered keratinocytes that progressively gain further mutations, most probably as a result of continued exposure to carcinogens, such as tobacco and alcohol. ${ }^{6-8}$ Mutated keratinocytes with growth advantage gradually expand and replace normal epithelial cells of the oral mucosa favouring the development of a second primary OSCC. ${ }^{9,10}$

Nevertheless, data sustaining the concept of field cancerization are difficult to reconcile with the development of dysplasia and squamous carcinoma in cutaneous skin grafted into the oral cavity.

To date, no molecular studies have been performed on squamous carcinomas arising on the grafted skin; furthermore, the clonal relationship between the primary OSCCs and the second neoplastic features appearing in the skin grafts still needs to be assessed, in order to differentiate recurrences from second primary OSCCs.

The high frequency rate of mtDNA mutations in tumours ${ }^{11-13}$ especially those found in the D-loop region, a non coding region, along with numerous mitochondrial genomes present in a single cell, makes mtDNA a reliable marker for clonality assays from microdissected paraffin-embedded tissue samples. ${ }^{14-16}$

We evaluated the clonal relationship between the primary cancer affecting the oral mucosa and the second neoplastic features appearing in the skin graft by screening the mtDNA D-loop region in three OSCC patients. 


\section{Case histories}

\section{Case 1}

In 2004, a 61 year old female, heavy smoker, presented with an ulcerated mass located in the retromolar trigone of the right mandible. An incisional biopsy diagnosed an invasive OSCC. Thereafter, the right mandible was surgically removed and substituted with a peroneal bone and an osteocutaneous flap comprising forearm skin. In February 2006 the patient presented an exophytic mass of the right maxillary gingiva, which was diagnosed as OSCC by an incisional biopsy. The patient underwent right maxillectomy with reconstruction. In April 2006 the patient presented a polypoid lesion located in the centre of the cutaneous mandibular graft used to reconstruct the defect caused by the surgical resection of the first OSCC. The lesion was surgically removed.

The patient has never discontinued smoking. She died of OSCC, 4 years after the first surgery.

\section{Case 2}

In February 2004 a 58 year old female patient presented with an ulcerated lesion of the mouth floor (Figure 1A), diagnosed by an incisional biopsy as invasive OSCC (Figure 1B). The patient was a heavy smoker and previous personal and familial anamneses were unremarkable. Radical surgical excision of the neoplastic mass was performed at the time and a cutaneous graft of forearm skin was used to repair the defect (Figure 1C). No radiotherapy was performed. The patient discontinued smoking and was put on followup. 
Four years later, in April 2008, an ulcerated lesion appeared at the periphery (Figure 1D) of the cutaneous graft, close to the margin with the oral mucosa. An incisional biopsy was performed to define the nature of the ulcer, diagnosing in situ OSCC of the cutaneous graft (Figure 1E). The lesion was then completely removed.

In October 2008, a third lesion was observed, consisting of an erythroplasic area located at the right side of the skin graft, with no spatial relationship with the in situ OSCC. Five years after the first surgical resection, the patient is alive, still on follow up, and free of neoplastic disease.

\section{Case 3}

In February 2005, a 52 year old male patient, heavy smoker, presented a leucoplasic area, ulcerated in the centre, in the anterior third of the right margin of the tongue. After the histological diagnosis of invasive OSCC, radical surgical excision of the neoplastic lesion was performed together with bilateral submandibular lymph node dissection. A forearm free flap was used to reconstruct the defect of the right margin of the tongue.

In august 2009, the patient presented an exophytic lesion with focal ulceration of the cutaneous graft used. The lesion was diagnosed as squamous cell carcinoma in incisional biopsy and thereafter, it was surgically removed.

Five months after the last surgical resection the patient is alive, on follow up, and free of neoplastic disease. 


\section{MATERIALS AND METHODS}

All tissues had been formalin fixed and paraffin embedded. Staging was performed according to the TNM staging system, ${ }^{17}$ grading was performed according to the criteria defined by Kademani et al. ${ }^{18}$ Moreover, in all three cases, the skin flap specimens which included the second tumours were all completely sampled for histological examination.

\section{Microdissection and mtDNA sequencing analysis}

Pertinent lesions were microdissected using the laser assisted SL $\mu$ cut microtest GmbH distributed by Nikon (Firenze, Italy, http://www.mmi-micro.com) as previously described. ${ }^{19-21}$ Different portions of normal epithelial tissue located far away from the neoplastic lesions were dissected and used as reference DNA sequence. DNA was extracted using the QIAamp® DNA Micro kit (Qiagen, Hilden, Germany) following the manufacturer's instructions. An extraction control, to which no tissue was added, was processed in parallel with each sample extraction. The mtDNA D-loop sequence analysis was performed by amplifying four overlapping segments of about $300 \mathrm{bp}$, covering the whole region from position 16056 to position 729, according to Anderson and colleagues $^{22}$ (see www.mitomap.org for revised Cambridge mtDNA reference sequence). Primers were designed using primer3 (http://www-genome.wi.mit.edu/cgibin/primer/primer3_www.cgi, see Table 2 for sequence details). These primers were selected to avoid amplification of human mitochondrial pseudogenes in the nuclear genome. $^{23}$ PCR products were directly sequenced using CEQ2000 XL instrument (Beckman Coulter, Inc., Fullerton, CA) following the instructions of the provider.

Phylogenetic and cluster analyses were conducted using MEGA software version 3.1 19-21 
(http://www.megasoftware.net ) using the neighbour joining method (NJ) ${ }^{24}$ and Kimura-2 parameter with Gamma model that corrects for multiple hits taking into account transitional and transversional substitution rates and differences in the site substitution rates. ${ }^{25}$ Every NJ tree was tested for standard error by the Bootstrap method. ${ }^{26}$

\section{RESULTS}

\section{Case 1}

Histology: histological examination of the tumour removed from the right mandible (indicated as T1 in the mtDNA analysis) confirmed the diagnosis of OSCC, staged T2N0M0, ${ }^{17}$ grade $3 .^{18}$ Resection margins were tumour free, but a small neoplastic nest was present close $(<5 \mathrm{~mm})$ to the medial margin.

The tumour of the right maxilla (indicated as T2 in the mtDNA analysis) was diagnosed as a second primary OSCC as it arose at a distance $>3 \mathrm{~cm}$ from the first OSCC and was staged T4N0M0, ${ }^{17}$ grade $3 .{ }^{18}$ All resection margins were tumour free (distance $>5 \mathrm{~mm}$ ).

The lesion on the skin graft (indicated as T3 in the mtDNA analysis) showed the epidermis filled with atypical keratinocytes appearing as in situ squamous cell carcinoma. ${ }^{27}$ In addition, nests of neoplastic cells invaded the superficial dermis. Therefore, the diagnosis of OSCC with early dermis invasion was reported. Resection margins were free of carcinoma and of dysplastic features.

mtDNA analysis: the phylogenetic neighbour joining tree revealed that the two normal epithelial samples (indicated as N1 and N2) clustered together while the three lesions should be considered independent entities with a clonal relationship between T1 (OSCC 
arising in the retromolar trigone of the right mandible) and T3 (the in situ OSCC arising on the skin graft) (Figure 2).

$\mathrm{T} 2$ (the OSCC arising in the maxilla) appears completely separated from $\mathrm{T} 1$ and $\mathrm{T} 3$ indicating lack of clonal relationship.

\section{Case 2}

Histology: the tumour affecting the floor of the mouth (indicated as T1 in the mtDNA analysis) was a conventional type of OSCC, staged T1N0M0, ${ }^{17}$ grade $2 .{ }^{18}$ All resection margins were tumour free, with a minimum distance between the tumour and the closest margin $>5 \mathrm{~mm}$.

The lesion appearing in the skin graft (T2) was characterised by the epidermis filled by atypical keratinocytes extending to the follicular infundibula replacing the follicular epithelium. This lesion met the criteria for in situ OSCC. ${ }^{27}$ The resection margins were free of tumour and dysplastic lesions.

The oral mucosa adjacent to the skin graft margin (T3) was composed of atypical keratinocytes, arranged in an irregular architecture, replacing the lower two-thirds of the squamous epithelium. Therefore, the diagnosis of moderate dysplasia was performed. ${ }^{27}$

mtDNA analysis: the phylogenetic neighbour joining tree showed a close genetic relationship between T1 and T2. On the contrary, the dysplastic lesion appeared in 2008 (T3) had several mutations not in common with the previous ones, a sign of wide genetic distance. As expected, in the tree, normal epithelia (N1, N2 and N3) were located far away from the four lesions (Figure 3). 


\section{$\underline{\text { Case } 3}$}

Histology: histological examination of the OSCC removed from the right margin of the tongue (indicated as T1 in the mtDNA analysis) showed features of a conventional well differentiated OSCC and no lymph node metastases were present. Thus, the tumour was staged T1N0M0, ${ }^{17}$ grade $2 .{ }^{18}$ The cancer was surrounded by an area of in situ carcinoma (T1IS). Resection margins were tumour free, however, a small neoplastic nest was present close (distance $<5 \mathrm{~mm}$ ) to the deep margin.

The histological analysis of the lesion developed in the skin graft (T2) showed the epidermis filled by atypical keratinocytes with the appearance of in situ squamous cell carcinoma. ${ }^{27}$ In addition, well differentiated invasive OSCC was present.

mtDNA analysis: the phylogenetic neighbour joining tree revealed that the two normal epithelial samples (N1 and N2) were clustered together, while the two lesions can be considered independent entities. Furthermore, a moderate relationship between the T1 in situ carcinoma (T1IS) and both the in situ carcinoma (T2IS) and the OSCC (T2) and arising from the skin graft was observed (Figure 4). However, T1 (the OSCC arising in the tongue) appeared to have no clonal relationship and was divergent from the other carcinomas. This might be the consequence of new random acquired mutations during cellular proliferation.

\section{DISCUSSION}

To define a second primary OSCC, mainly clinical criteria, such as distance between the first and the second primary tumour $>2 \mathrm{~cm}$ or time interval between the tumours $>3$ 
years, have been proposed. ${ }^{28}$ However, increasing evidence suggests that in some cases, regardless of clinical characteristics, primary and second tumours may have a common clonal origin.

Several methods are nowadays available to assess the clonal relationship between two lesions. Clonal assessment by mtDNA analysis ${ }^{29}$ is based on the concept that mitochondrial DNA is present in a high copy number in each cell $\left(10^{3}-10^{4}\right)$ and that the vast majority of these copies are identical at birth (homoplasmic). In other words, neoplastic cells preserve the high copy number but show a high frequency of mutations in the mtDNA especially in the D-loop region. Coller et al. ${ }^{12}$ demonstrated that the mtDNA D-loop region is not involved in transformation and disease progression, since it would appear that mutations in this mtDNA segment do not offer a proliferation advantage to the cell. Therefore, these acquired mutations may be considered a reliable marker to assess clonality as previously indicated. ${ }^{14-16}$

In all three present cases the neoplastic lesions arising in the skin graft showed a clonal relationship with the previous OSCC. Therefore, on the basis of the results obtained with mtDNA analysis, the present cases of OSCC arising in the skin graft can be considered a recurrence of the primary OSCC rather than a second primary OSCC.

However, these results seem difficult to reconcile with the clinical and histological features of these cases. All lesions arising in the skin graft were characterized by the presence of in situ OSCC. Furthermore, in cases two and three, the skin graft lesions developed more that 3 and 5 years after the removal of the first OSCC, respectively. These observations are difficult to reconcile with the molecular analysis which shows a clonal relationship between the primary OSCC and the neoplastic lesion affecting the 
graft. However, it should be kept in mind that we are dealing with skin grafted in the oral cavity and, as it is well known, skin tumour cells can spread through the epidermis, as commonly seen in Borst-Jadasson phenomenon, ${ }^{30}$ horizontal growth of melanomas and Paget disease of the nipple.

All these phenomena, that are a part of routine surgical pathology, have been explained by demonstrating the capacity of epidermal keratinocytes to produce cytokines that allow and induce the cell movements.

Currently available data indicate that the skin basically maintains its morphology, even when implanted in the oral cavity. Indeed, diseases typically affecting the skin such as psoriasis $^{31}$ and focal acantholytic dyskeratosis ${ }^{32}$ have been reported in skin grafts. Therefore, it is not implausible to think that skin grafted into the oral cavity may retain its ability to produce cytokines continuing to give its instructive signals. ${ }^{4}$

Taken together, our results suggest that single neoplastic cells from the original OSCC can spread laterally, reach the epidermis of the skin graft and implant there giving rise to the OSCC.

The hypothesis of an intra-epithelial spread of neoplastic keratinocytes in the oral cavity has been proposed and described as the "patch-field-carcinoma model" by Braakhius and colleagues. ${ }^{7}$ Starting from a patch of genetically altered cells, through a clonal expansion in a lateral direction, a field lesion develops and gradually grows taking over the normal epithelium. Within this genetically altered field, a transforming event eventually leads to the development of a subclone with invasive growth that turns into a carcinoma.

Within this background, it is possible that after radical resection of the tumour, the genetically altered field is still present in the patient. Therefore, the field expansion 
continues and may spread into the skin graft used to reconstruct the tissue defect and be the cause of a new cancer.

In conclusion, primary OSCC and tumours arising from grafted skin might develop from a common genetically altered field. Moreover, the spreading of the clonal cell population to the cutaneous flap might be stimulated by cytokines produced by the grafted skin.

More studies are needed to evaluate the molecular relationship between primary and second OSCC in order to identify those patients who are at higher risk of developing a second tumour and thus require a more accurate long-term follow-up. 


\section{REFERENCES}

1. Song R, Gao Y, Song Y, Yu Y, Song Y. The forearm flap. Clin Plast Surg 1982;9;21-26.

2. Licciardello JT, Spitz MR, Hong WK. Multiple primary cancer in patients with cancer of the head and neck: second cancer of the head and neck, esophagus, and lung. Int J Radiat Oncol Biol Phys 1989;17;467-476.

3. Sinclair A, Johnston E, Badran DH et al. Histological changes in radial forearm skin flaps in the oral cavity. Clin Anat 2004;17;227-232.

4. Badran D, Soutar DS, Robertson AG et al. Behavior of radial forearm skin flaps transplanted into the oral cavity. Clin Anat 1998;11;379-389.

5. Slaughter DP, Southwick HW, Smejkal W. Field cancerization in oral stratified squamous epithelium; clinical implications of multicentric origin. Cancer 1953;6;963968.

6. Califano J, van der Riet P, Westra W et al. Genetic progression model for head and neck cancer: implications for field cancerization. Cancer Res 1996;56;2488-2492.

7. Braakhuis BJ, Leemans CR, Brakenhoff RH. A genetic progression model of oral cancer: current evidence and clinical implications. J Oral Pathol Med 2004;33;317-322.

8. Lumerman H, Freedman P, Kerpel S. Oral epithelial dysplasia and the development of invasive squamous cell carcinoma. Oral Surg Oral Med Oral Pathol Oral Radiol Endod 1995;79;321-329.

9. Braakhuis BJ, Leemans CR, Brakenhoff RH. Expanding fields of genetically altered cells in head and neck squamous carcinogenesis. Semin Cancer Biol 2005;15;113120.

10. Tabor MP, Brakenhoff RH, Ruijter-Schippers HJ et al. Multiple head and neck tumors frequently originate from a single preneoplastic lesion. Am J Pathol 2002;161;1051-1060.

11. Fliss MS, Usadel H, Caballero OL et al. Facile detection of mitochondrial DNA mutations in tumors and bodily fluids. Science 2000;287;2017-2019.

12. Coller HA, Khrapko K, Bodyak ND, Nekhaeva E, Herrero-Jimenez P, Thilly WG. High frequency of homoplasmic mitochondrial DNA mutations in human tumors can be explained without selection. Nat Genet 2001;28;147-150.

13. Richard SM, Bailliet G, Paez GL, Bianchi MS, Peltomaki P, Bianchi NO. Nuclear and mitochondrial genome instability in human breast cancer. Cancer Res 2000;60;42314237.

14. Morandi L, Pession A, Marucci GL et al. Intraepidermal cells of Paget's carcinoma of the breast can be genetically different from those of the underlying carcinoma. Hum Pathol 2003;34;1321-1330.

15. Morandi L, Marucci G, Foschini MP et al. Genetic similarities and differences between lobular in situ neoplasia $(\mathrm{LN})$ and invasive lobular carcinoma of the breast. Virchows Arch 2006;449;14-23.

16. Morandi L, Asioli S, Cavazza A, Pession A, Damiani S. Genetic relationship among atypical adenomatous hyperplasia, bronchioloalveolar carcinoma and adenocarcinoma of the lung. Lung Cancer 2007;56;35-42.

17. AJCC. Cancer Staging Handbook (7th edition). New York: Springer, 2010. 
18. Kademani D, Bell RB, Bagheri S et al. Prognostic factors in intraoral squamous cell carcinoma: the influence of histologic grade. J Oral Maxillofac Surg 2005;63;15991605.

19. Kumar S, Gadagkar SR. Efficiency of the neighbor-joining method in reconstructing deep and shallow evolutionary relationships in large phylogenies. $J$ Mol Evol 2000;51;544-553.

20. Kumar S, Tamura K, Jakobsen IB, Nei M. MEGA2: molecular evolutionary genetics analysis software. Bioinformatics 2001;17;1244-1245.

21. Saitou N, Nei M. The neighbor-joining method: a new method for reconstructing phylogenetic trees. Mol Biol Evol 1987;4;406-425.

22. Anderson S, Bankier AT, Barrell BG et al. Sequence and organization of the human mitochondrial genome. Nature 1981;290;457-465.

23. Woischnik M, Moraes CT. Pattern of organization of human mitochondrial pseudogenes in the nuclear genome. Genome Res 2002;12;885-893.

24. Kumar S, Tamura K, Nei M. MEGA: Molecular Evolutionary Genetics Analysis software for microcomputers. Comput Appl Biosci 1994;10;189-191.

25. Kimura M. A simple method for estimating evolutionary rates of base substitutions through comparative studies of nucleotide sequences. J Mol Evol 1980;16;111-120.

26. Efron B, Tibshirani R. An introduction to the bootstrap. New York: Chapman \& Hall. 1993.

27. Barnes L, Eveson JW, Reichart P, Sidranski D. Pathology and Genetics Head and Neck Tumours, World Health Classification of Tumours. Lyon, 2005.

28. Braakhuis BJ, Tabor MP, Leemans CR, van der Waal I, Snow GB, Brakenhoff RH. Second primary tumors and field cancerization in oral and oropharyngeal cancer: molecular techniques provide new insights and definitions. Head Neck 2002;24;198-206.

29. Morandi L, Marucci GL, Pession A, Eusebi V. DNA mitocondriale e CGH array in patologia mammaria. Pathologica 2005;97;188-189.

30. Helm KF, Helm TN, Helm F. Borst-Jadassohn phenomenon associated with an undifferentiated spindle cell neoplasm. Int J Dermatol 1994;33;563-565.

31. Dimitrakopoulos I, Lazaridis N, Scordalaki A. Dermal psoriasis involving an oral split-skin graft. Case report. Aust Dent J 1998;43;321-323.

32. Hurwitz H, Fehrenbacher L, Novotny W et al. Bevacizumab plus irinotecan, fluorouracil, and leucovorin for metastatic colorectal cancer. $N$ Engl J Med 2004;350;2335-2342.

33. Deans JA, Hill J, Welch AR, Soames JV. Late development of a squamous carcinoma in a reconstructed pharynx. J Laryngol Otol 1990;104;827-828.

34. Iseli TA, Hall FT, Buchanan MR, Kleid SM. Squamous cell carcinoma arising in the skin of a deltopectoral flap 27 years after pharyngeal reconstruction. Head Neck 2002;24;87-90.

35. Monnier Y, Pasche P, Monnier P, Andrejevic-Blant S. Second primary squamous cell carcinoma arising in cutaneous flap reconstructions of two head and neck cancer patients. Eur Arch Otorhinolaryngol 2008;265;831-835.

36. Sa'do B, Nakamura N, Higuchi Y, Ozeki S, Harada H, Tashiro H. Squamous cell carcinoma of the oral cavity derived from a skin graft: a case report. Head Neck 1994;16;79-82. 
37. Sakamoto M, Nibu K, Sugasawa M, Nakatsuka T, Harii K, Ichimura K. A second primary squamous cell carcinoma arising in a radial forearm flap used for reconstruction of the hypopharynx. ORL J Otorhinolaryngol Relat Spec 1998;60;170-173.

38. Scott MJ, Klaassen MF. Squamous cell carcinoma in a tube pedicle forty years after jaw reconstruction. Br J Plast Surg 1992;45;70-71.

\section{Conflict of interest statement}

None declared 
Table 1 - Cases of carcinoma developed from skin grafts

\begin{tabular}{|l|c|c|c|c|c|}
\hline Author [ref] & Year & $\begin{array}{c}\text { N. of } \\
\text { cases }\end{array}$ & Site of tumour & $\begin{array}{c}\text { Tumour } \\
\text { histology }\end{array}$ & $\begin{array}{c}\text { Interval between } \\
\text { grafting and } \\
\text { recurrence }\end{array}$ \\
\hline Deans et al. $^{33}$ & 1990 & 1 & Larynx & SCC & 24 years \\
\hline Iseli et al. $^{34}$ & 2002 & 1 & Larynx & SCC & 27 years \\
\hline Monnier et al. $^{35}$ & 2008 & 2 & Oral mucosa & SCC & $3,5-20$ years \\
\hline Sa'do et al. $^{36}$ & 1994 & 1 & Lower gum & SCC & 19 years \\
\hline Sakamoto et al. & 1998 & 1 & Hypopharynx & SCC & 10 years \\
\hline Scott et al. & 1992 & 1 & Pharynx & SCC & 40 years \\
\hline Present cases & 2009 & 3 & $\begin{array}{c}\text { Oral mucosa, } \\
\text { tongue }\end{array}$ & SCC & $2-4$ years \\
\hline
\end{tabular}

SCC: Squamous Cell Carcinoma; RT: Radiotherapy.

Table 2 - Primers for mtDNA D-loop sequence analysis

\begin{tabular}{|l|l|}
\hline Primer & Sequence \\
\hline Primer1 & CCAAGTATTGACTCACCCATCAAC \\
\hline Primer2 & TGTGCGGGATATTGATTTCACG \\
\hline Primer3 & TGAAATCAATATCCCGCACA \\
\hline Primer4 & GGATGAGGCAGGAATCAAAG \\
\hline Primer5 & GAGCTCTCCATGCATTTGGT \\
\hline Primer6 & TGGTTAGGCTGGTGTTAGGG \\
\hline Primer7 & CCCTAACACCAGCCTAACCA \\
\hline Primer8 & AGGGTGAACTCACTGGAACG \\
\hline
\end{tabular}




\section{FIGURE LEGEND}

Figure 1: Macroscopic view (A) and histology (B) of the primary OSCC; skin graft placed to repair the mucosal defect (C); macroscopic view (D) and histology (E) of the SCC on the skin graft.

Figure 2: Phylogenetic neighbour joining tree of case 1.

Figure 3: Phylogenetic neighbour joining tree of case 2.

Figure 4: Phylogenetic neighbour joining tree of case 3. 


\section{Acknowledgements}

Work financed by grants from the Ministry of the University and Research (Fund ex 40\% "Fundamental Oriented Research") and Regione Emilia Romagna (Funds: Region University Research Program 2007-2009, Project Oncology).

AF is supported by "Vanda Vanini e Sandro Cavagnino" grants. 


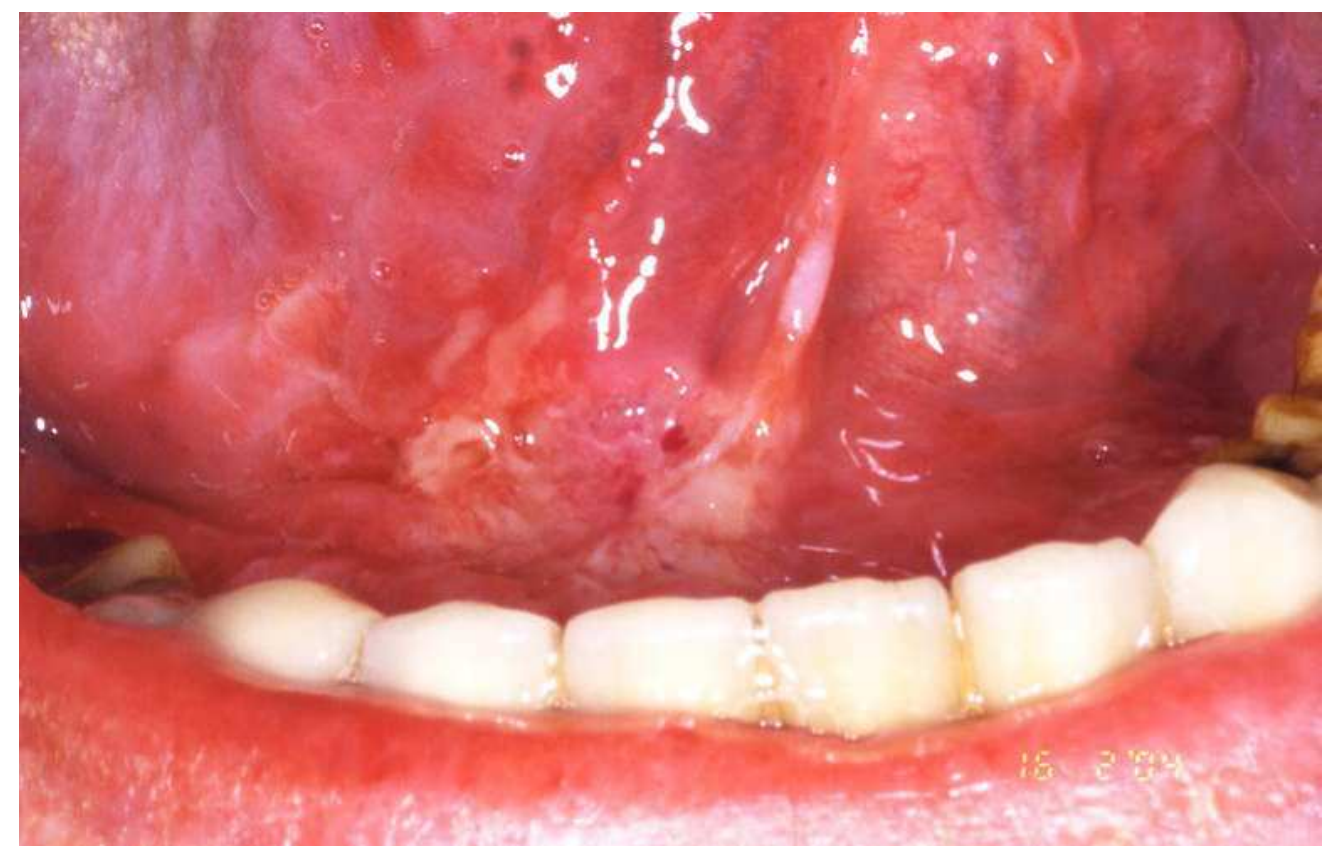

Macroscopic view of the primary OSCC $65 \times 42 \mathrm{~mm}(300 \times 300 \mathrm{DPI})$ 


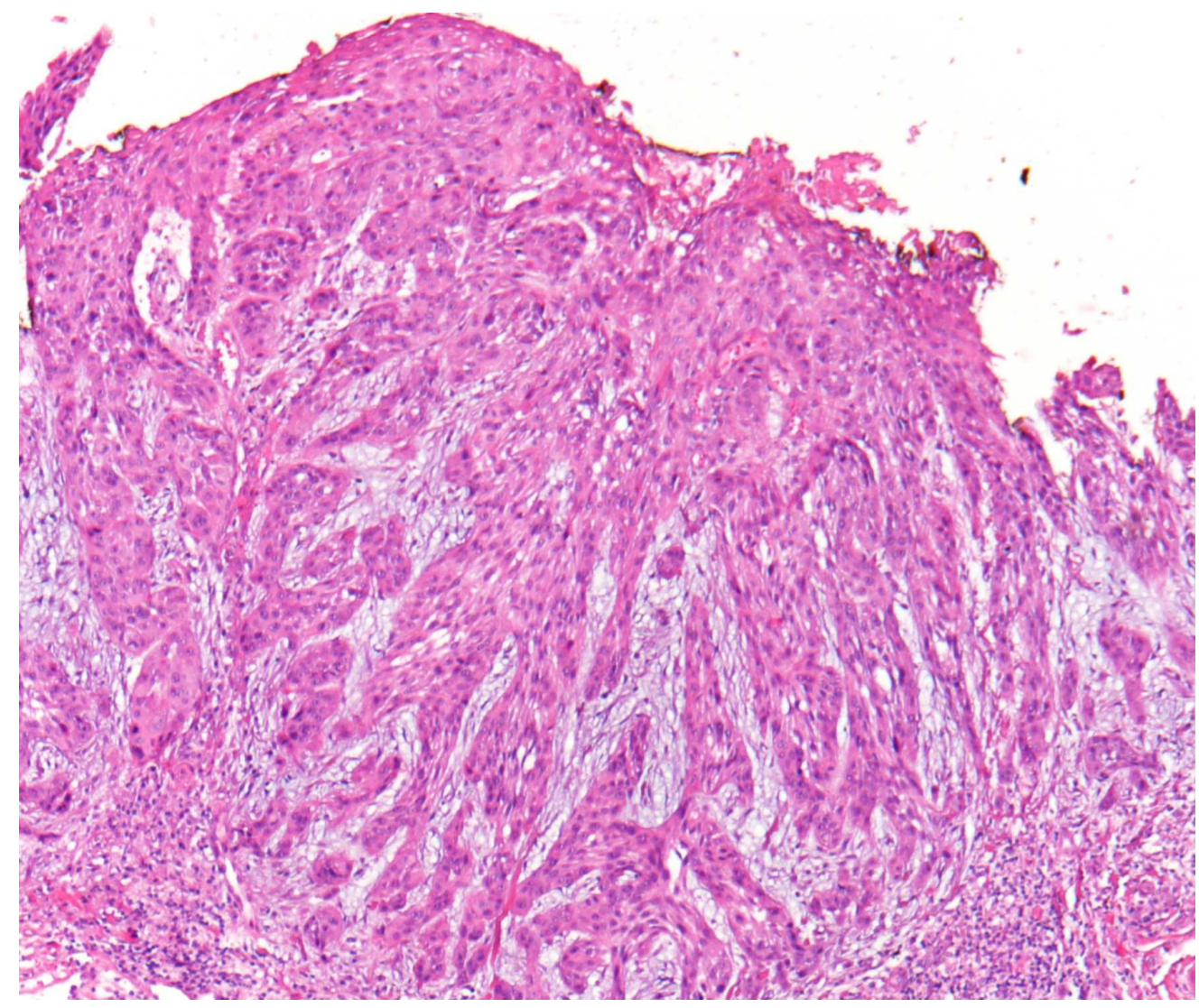

Histology of the primary OSCC $150 \times 126 \mathrm{~mm}(300 \times 300 \mathrm{DPI})$ 


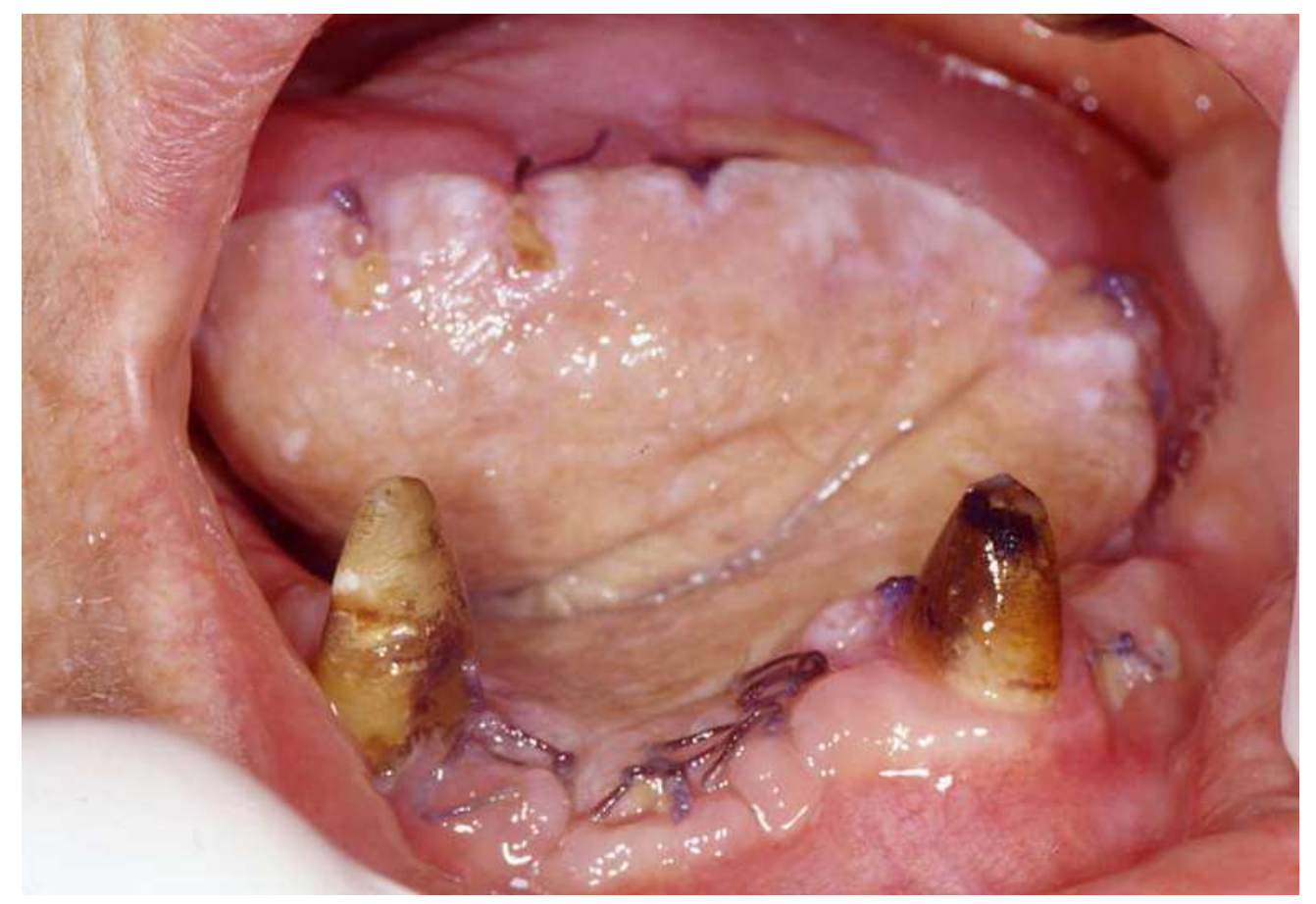

Skin graft placed to repair the mucosal defect $65 \times 45 \mathrm{~mm}(300 \times 300 \mathrm{DPI})$ 


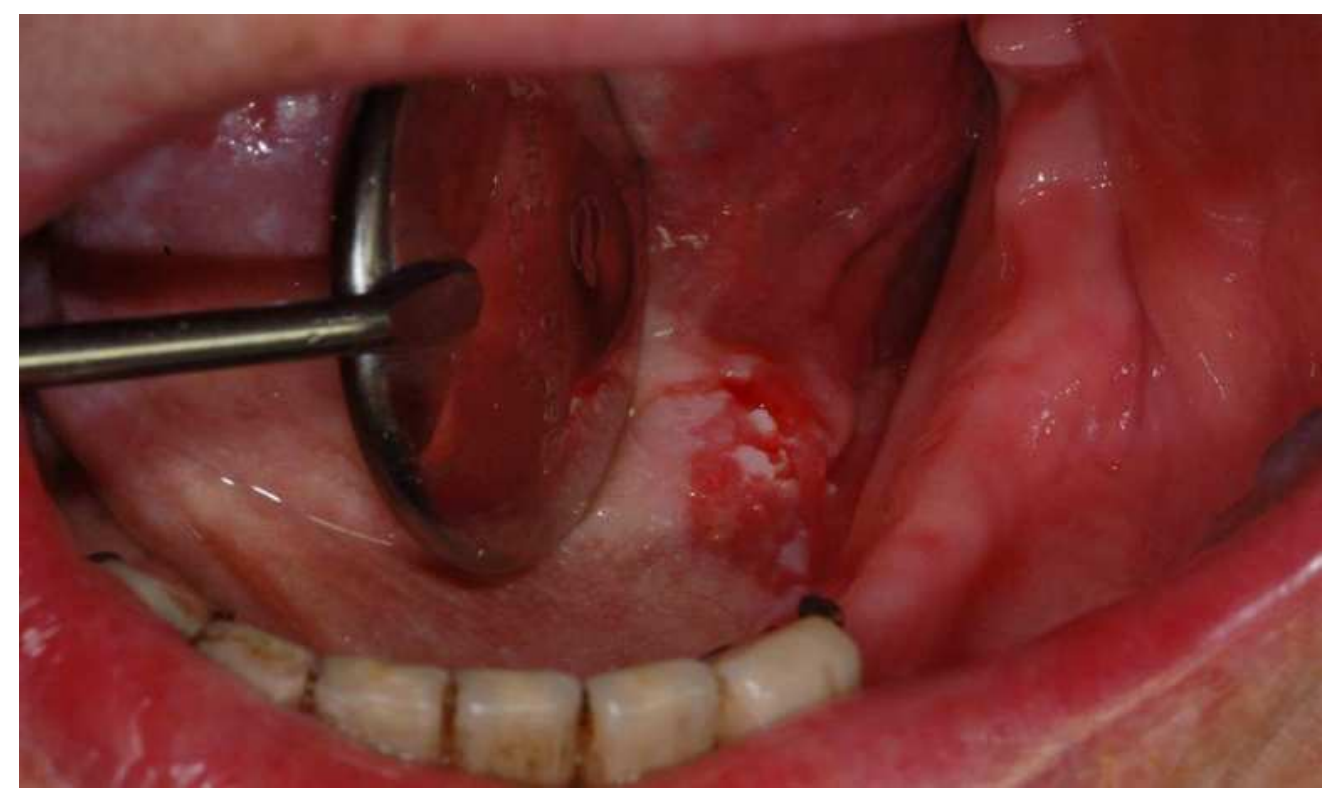

Macroscopic view of the SCC arised on the skin graft $65 \times 39 \mathrm{~mm}(300 \times 300 \mathrm{DPI})$ 


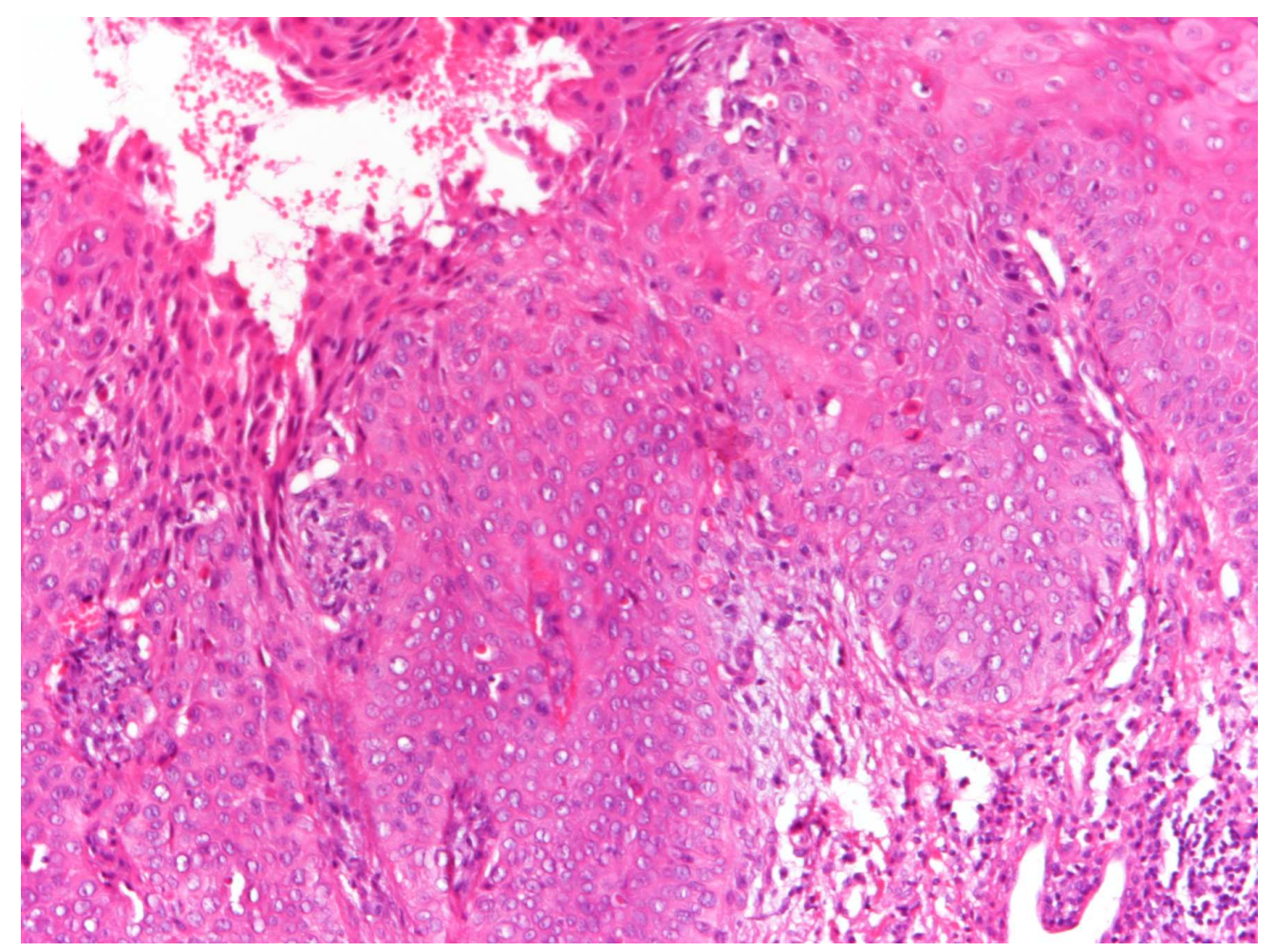

Histology of the SCC arised on the skin graft $150 \times 112 \mathrm{~mm}(300 \times 300 \mathrm{DPI})$ 


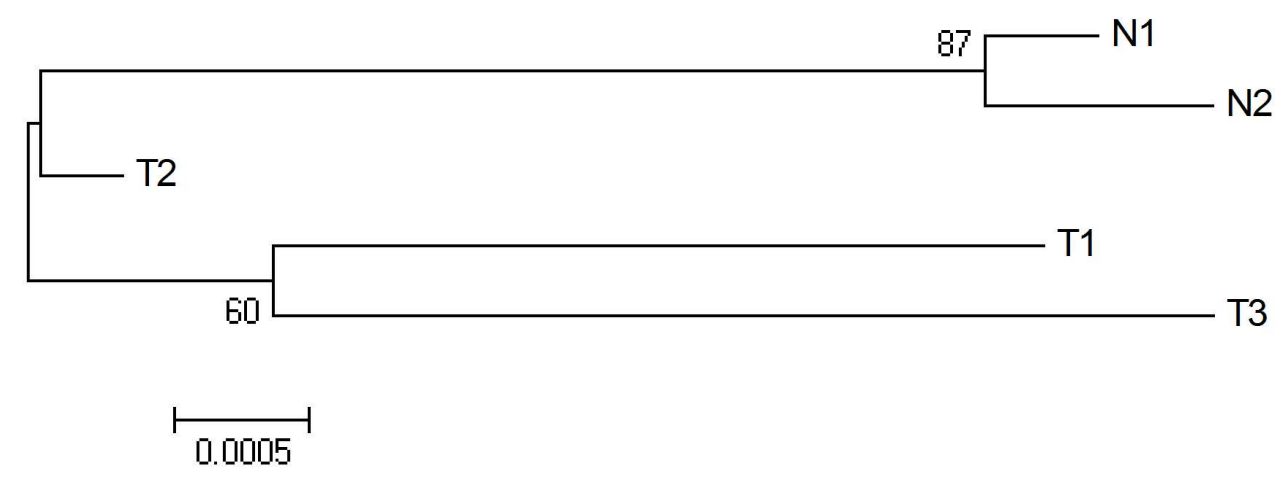

Phylogenetic neighbour joining tree of case 1 $113 \times 44 \mathrm{~mm}(400 \times 400 \mathrm{DPI})$ 


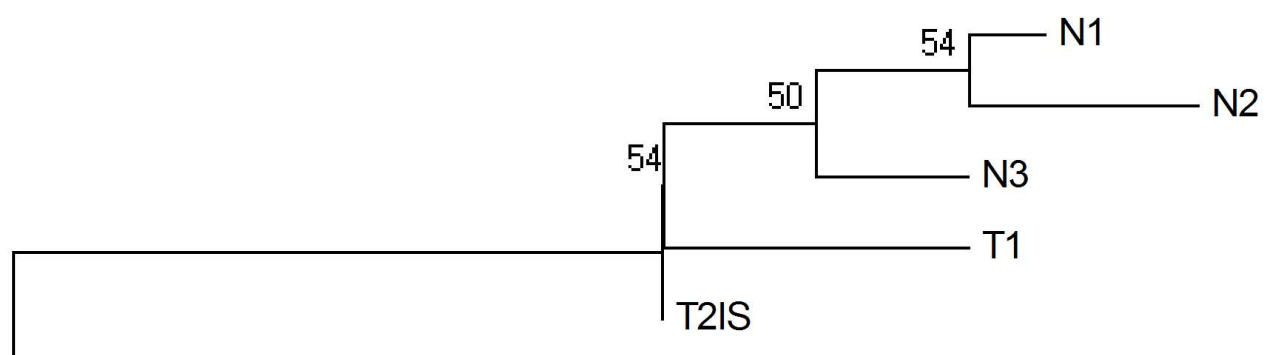

$\longmapsto 0.005$

Phylogenetic neighbour joining tree of case 2 $111 \times 50 \mathrm{~mm}(400 \times 400 \mathrm{DPI})$ 


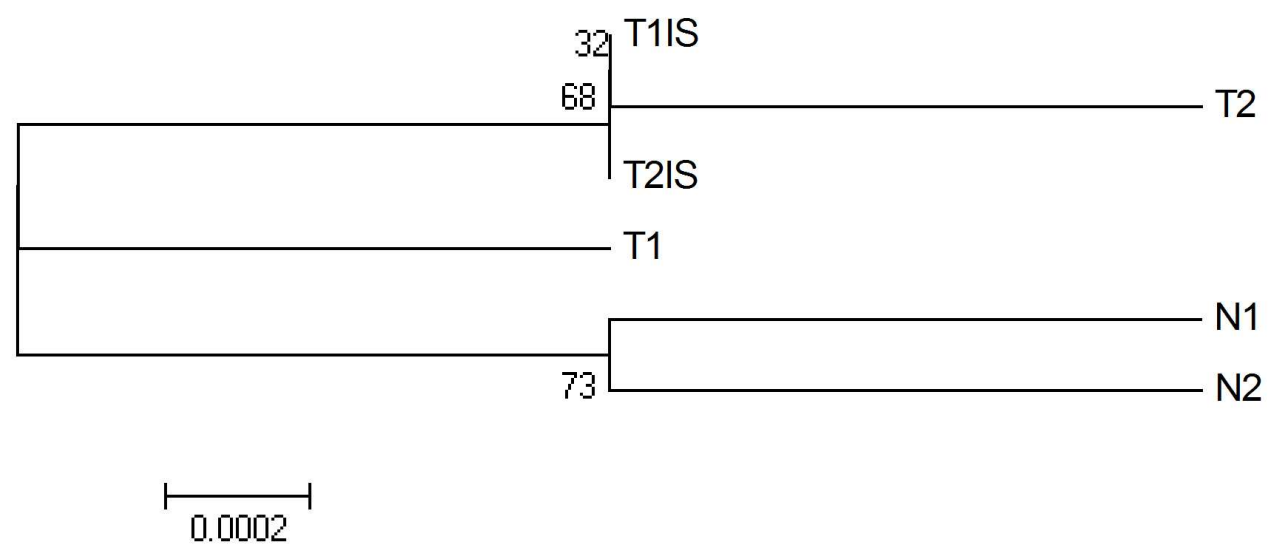

Phylogenetic neighbour joining tree of case 3 $111 \times 50 \mathrm{~mm}(400 \times 400$ DPI $)$ 